\title{
Spontaneous Regression of an Asymptomatic Meningioma Associated With Discontinuation of Progesterone Agonist Administration
}

\author{
-Case Report-
}

\author{
Jun SHIMIZU, Masayoshi Matsumoto, \\ Etsuo YAMAZAKI*, and Masaharu YASUE
}

Departments of Neurosurgery and *Radiology, Japanese Red Cross Hospital Ohmori, Tokyo

\begin{abstract}
An 80-year-old male visited the hospital as an outpatient with a head injury sustained in a traffic accident. Brain computed tomography incidentally revealed a left frontal lobe tumor measuring $5 \mathrm{~cm}$ in a diameter. The patient had a history of taking chlormadinone acetate (a progesterone agonist) prescribed several years previously as treatment for benign prostatic hypertrophy. The tumor was seen as an isointense lesion on $\mathrm{T}_{1}$-weighted magnetic resonance (MR) images with enhancement by gadolinium, and as a heterogeneously hyperintense mass on $T_{2}$-weighted $M R$ images. The tentative diagnosis was left frontal meningioma attached to the sphenoid ridge or sphenoid plane. The patient was managed conservatively because of his advanced age and no symptoms or progression were observed during a 9-month follow-up period. The medication for benign prostatic hypertrophy was changed from chlormadinone acetate to naftopidil (an alpha-2-blocker) about 9 months after his first presentation. The patient presented again 2 years later complaining of dizziness. Computed tomography and MR imaging performed at this time revealed remarkable regression of the tumor. The signal intensity change with regression of the tumor on $\mathrm{T}_{2}$-weighted images was observed as a hypointense lesion. Thus, we wish to emphasize that treatment of meningiomas, especially those diagnosed incidentally, must be based on a thorough consideration of any history of hormonal therapy with prostate disease.
\end{abstract}

Key words: asymptomatic meningioma, progesterone agonist, spontaneous regression, prostate

\section{Introduction}

Meningioma is a benign tumor arising from the arachnoid cap cells or meningothelial cells, and is reported to account for $20-26.2 \%$ of all primary intracranial tumors. ${ }^{2,3)}$ However, increased use of computed tomography (CT) and magnetic resonance (MR) imaging has increased the frequency of detection of asymptomatic meningiomas. ${ }^{11)}$

Previous studies have reported the expression of sex hormone receptors in meningiomas. ${ }^{1,9,20)}$ Meningiomas reportedly enlarge when the serum levels of progesterone are elevated during pregnancy or the luteral phase of menstrual cycle in women. ${ }^{9)}$ Here we report a male patient with spontaneous regression of an asymptomatic meningioma associated with discontinuation of progesterone agonist administration that he was receiving for the treatment of benign prostatic hypertrophy.

\section{Case Report}

An 80-year-old male visited our hospital as an outpatient in March 2003 with a head injury sustained in a traffic accident. His past medical history included a several years' history of benign prostatic hypertrophy and angina pectoris, and had been taking chlormadinone acetate (a progesterone agonist) for several years, prescribed at another hospital as treatment for benign prostatic hypertrophy.

Neurological examinations revealed no abnormalities. Brain CT showed a left frontal lobe tumor

Received June 25, 2007; Accepted January 11, 2008

Author's present address: J. Shimizu, M.D., Medical Engineering Laboratory, Research Center for Medical Science, The Jikei University School of Medicine, Tokyo, Japan. 

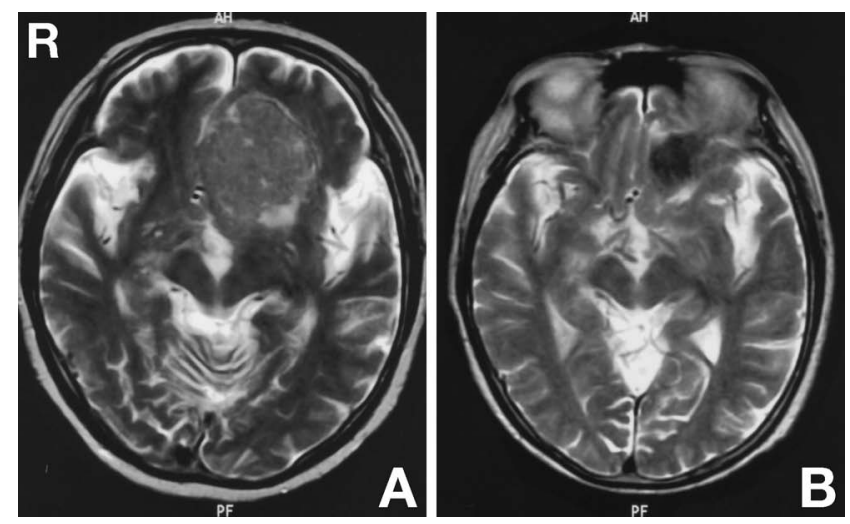

Fig. $1 \mathrm{~T}_{2}$-weighted magnetic resonance images showing signal intensity change from heterogeneously hyperintense (A) to hypointense (B) with regression of the tumor on the axial image.
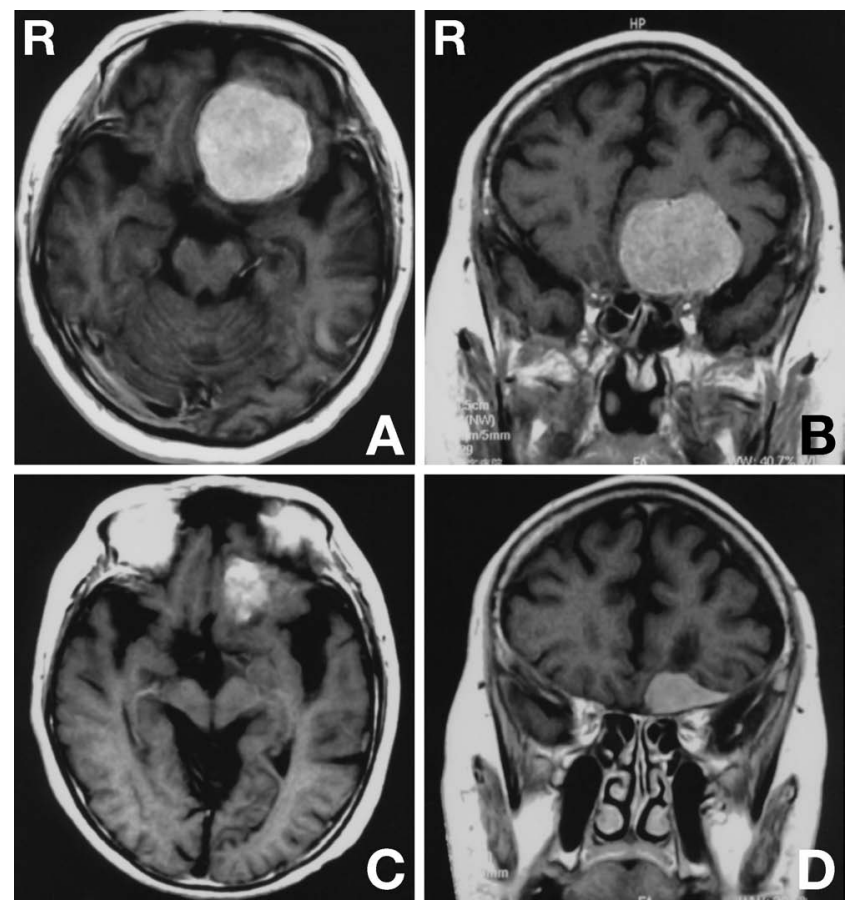

Fig. 2 Initial $T_{1}$-weighted magnetic resonance (MR) images with gadolinium showing an enhanced tumor measuring $5 \mathrm{~cm}$ in diameter attached to the left frontal base on the axial image (A), and on the coronal image (B). Follow-up $T_{1}$-weighted $M R$ images with gadolinium showing remarkable regression of the tumor at 2 years 9 months after the initial presentation (C, D).

measuring $5 \mathrm{~cm}$ in diameter that showed contrast enhancement and contained unremarkable calcifi- cations. The tumor appeared as an isointense mass lesion on $\mathrm{T}_{1}$-weighted MR images and a heterogeneously hyperintense lesion on $\mathrm{T}_{2}$-weighted MR images (Fig. 1A), with clear contrast enhancement on $\mathrm{T}_{1}$-weighted gadolinium MR images (Fig. 2A, B). No elevations in the serum levels of tumor markers (carcinoembryonic antigen, carbohydrate antigen 19-9, and alpha fetoprotein) were noted. The neuroimaging diagnosis was left frontal meningioma attached to the sphenoid ridge or sphenoid plane.

The tumor was managed conservatively because of his advanced age, and the absence of any symptoms or progression noted during an observation period of 9 months. The patient's medication for the treatment of benign prostatic hypertrophy was changed from chlormadinone acetate to naftopidil (an alpha-1 blocker) administered at the $25 \mathrm{mg} /$ day in December 2003.

The patient presented again in November 2005 complaining of dizziness. CT revealed marked regression of the tumor, which still showed contrast enhancement. $\mathrm{T}_{1}$-weighted gadolinium $\mathrm{MR}$ images also revealed remarkable regression of the tumor (Fig. 2C, D). The tumor appeared as isointense on $\mathrm{T}_{1^{-}}$ weighed $M R$ images and hypointense on $\mathrm{T}_{2}$-weighted images (Fig. 1B). The patient visited us again in February 2007 and neuroimaging showed no evidence of the tumor growth.

\section{Discussion}

The relationship between meningioma and sex hormones is well known, with the tumor occurring at a higher incidence in females, documented association with breast cancer in the same patient, and reports of exacerbation of symptoms during pregnancy and the luteal phase of the menstrual cycle. ${ }^{10)}$ The progesterone receptor is expressed in $61 \%$ to $95 \%$ of meningiomas, and the estrogen receptor in $0 \%$ to $8.6 \%$ of the tumor. ${ }^{1,9,20)}$ Based on the reported relationship between the progesterone receptor expression and a good prognosis, hormonal therapy has been tried for the treatment of meningiomas.9)

Endocrine manipulation of meningiomas in vitro was mainly attempted using medroxyprogesterone acetate as an agonist of the progesterone receptor in the 1980 s, ${ }^{13-15,22)}$ but no clinical efficacy could be confirmed. Mifepristone was used as a progesterone receptor antagonist in an in vitro study for the suppression of meningioma growth in $1986,{ }^{19)}$ and used to treat unresectable meningiomas in 1991.8) Administration of another antiprogesterone agent, onapristone, resulted in marked reduction of the meningioma size in both in vitro and in vivo studies. ${ }^{16)}$ However, no antiprogesterone therapies have 
Table 1 Cases of spontaneous meningioma regression associated with discontinuation of chlormadinone acetate

\begin{tabular}{lclccc}
\hline \multicolumn{1}{c}{ Author (Year) } & Age (yrs)/Sex & Presentation & Tumor location & Regression period & Outcome \\
\hline Fushimi et al. (2004) & 77/M & convulsions & rt frontal & 3 mos & good recovery \\
Present case & $80 / \mathrm{M}$ & asymptomatic & lt frontal & 2 yrs & good recovery \\
\hline
\end{tabular}

been established yet for the treatment of meningiomas. ${ }^{7)}$

One study found that $63 \%$ of asymptomatic meningiomas did not exhibit tumor growth, and only $6 \%$ of all patients with lesions experienced symptoms during the observation period. ${ }^{23)}$ In addition, the morbidity rate of surgically treated asymptomatic meningiomas was $4.4 \%$ among patients who were younger than 70 years old and $9.4 \%$ in those aged 70 years old or over.

There has been only one previous report of the meningioma regression associated with endocrine therapy (Table 1). Meningioma regression after the discontinuation of chlormadinone acetate prescribed for benign prostatic hypertrophy was reported in a 77-year-old male with a 7-year history of taking the medication (100 mg/day) after prostatic surgery.5) The patient presented with generalized convulsions and coma. Brain CT revealed an angiographically hypervascular mass lesion with a diameter of $8 \mathrm{~cm}$ at the right frontal base. The tentative diagnosis was meningioma, but tumor resection was not selected because the mental disorders might be induced by surgical injury of bilateral frontal lobes. The patient was treated conservatively with the discontinuation of chlormadinone acetate therapy for the reason of dysphagia. Three months later, MR imaging confirmed spontaneous regression of the tumor, and the patient's clinical symptoms and activities of daily living gradually improved. MR imaging was performed every 3 months, and progressed tumor regression was confirmed 9 months later.

Some reports have suggested the association of meningioma growth with endocrine therapy for genitourinary disease. One report described a female patient with a low-grade endometrial stromal sarcoma that was treated by total abdominal hysterectomy and bilateral salpingo-oophorectomy, who developed multiple meningiomas after receiving the progesterone agonist megasterol acetate for 19 years. ${ }^{6)}$ Two male cases of proliferation of skullbased meningiomas were reported after administration of a luteinizing hormone-releasing hormone agonist for prostate cancer. ${ }^{12)}$ An in vitro study has also reported meningioma cell proliferation in the presence of the luteinizing hormone-releasing hormone. ${ }^{4)}$
Reports of meningioma regression in other cases are rare. A female case has been reported with regression 4 years after tumor resection, but there was no relationship with endocrine factors. ${ }^{17)}$ Another female case showed increased growth of the tumor during pregnancy as well as postpartum clinical regression. ${ }^{21}$ The present case and one previous patient ${ }^{5}$ were men, who had received chlormadinone acetate for several years as a treatment for benign prostatic hypertrophy before the primary diagnosis of the tumor.

In our case, the endocrinological influence of progesterone agonist might be considered to have been involved in the increase in the size of meningioma by increasing the blood volume and the volume of extracellular and intracellular fluid in the tumor, as well as by inducing growth and proliferation of the tumor tissue like the pregnancy period. ${ }^{21)}$ In contrast to women, men have very low endogenous progesterone levels, and chronic administration of chlormadinone acetate might stimulate the development of incidental tumors showing strong progesterone receptor expression before the first neuroimaging presentation. ${ }^{6,21)}$

Since no histological or endocrinological diagnoses were established in our case, the marked signal intensity change observed with regression of the tumor from heterogeneous intense to hypointense on the $\mathrm{T}_{2}$-weighted $\mathrm{MR}$ images suggested that the biological feature of the tumor had altered into low growth potentiality. ${ }^{18)}$ The mechanism of spontaneous tumor regression may involve the decline in the progesterone levels after the discontinuation of chlormadinone acetate leading to the decrease in tumor volume and peritumoral edema as a result of the obstructed feeding arteries or tumor necrosis of the surrounding tissue. ${ }^{17,21)}$

This very unusual report of spontaneous regression of asymptomatic meningioma associated with discontinuation of chlormadinone acetate indicates that the treatment of incidental meningiomas must consider the patient's medication history, especially in elderly patients undergoing endocrine therapy for prostate disease. ${ }^{11,12)}$

\section{References}

1) Brandis A, Mirzai S, Tatagiba M, Walter GF, Samii 
M, Ostertag H: Immunohistochemical detection of female sex hormone receptors in meningiomas: correlation with clinical and histological features. Neurosurgery 33: 212-217, 1993

2) Committee of Brain Tumor Registry of Japan: Report of Brain Tumor Registry of Japan (1969-1996), 11th edition. Neurol Med Chir (Tokyo) 43 Suppl: i-vii, 1-111, 2003

3) DeAngelis LM: Brain tumors. $N$ Engl J Med 344: 114-123, 2001

4) Durmaz R, Deliorman S, Isiksoy S, Uyar R, Tel E: Luteinizing hormone releasing hormone increases proliferation of meningioma cells in vitro. Arch Physiol Biochem 107: 286-291, 1999

5) Fushimi S, Fukuchi M, Yonetani M: [Remarkable regression of right frontal base meningioma with termination of anti-testosterone agent. Case report] (author's translation). Akitaken Nouson Igakukai Zasshi 2: 91, 2004 (Jpn, with no abstract)

6) Gruber T, Dare AO, Balos LL, Lele S, Fenstermaker RA: Multiple meningiomas arising during long-term therapy with the progesterone agonist megasterol acetate. Case report. J Neurosurg 100: 328-331, 2004

7) Grunberg SM, Weiss MH, Russell CA, Spitz IM, Ahmadi J, Sadun A, Sitruk-Ware R: Long-term administration of mifepristone (RU486): clinical tolerance during extended treatment of meningioma. Cancer Invest 8: 727-733, 2006

8) Grunberg SM, Weiss MH, Spitz IM, Ahmadi J, Sadun A, Russell CA: Treatment of unresectable meningiomas with the antiprogesterone agent mifepristone. J Neurosurg 74: 861-866, 1991

9) Hsu DW, Efird JT, Edley-Whyte ET: Progesterone and estrogen receptors in meningiomas: prognostic considerations. J Neurosurg 86: 113-120, 1997

10) Konstantinidou AE, Korkopoulou $P$, Mahera $H$, Hranioti S, Eftychiadis C, Patsouris E: Hormone receptors in non-malignant meningiomas correlate with apotosis, cell proliferation and recurrence-free survival. Histopathology 43: 280-290, 2003

11) Kuratsu J, Kochi M, Ushio Y: Incidence and clinical features of asymptomatic meningiomas. J Neurosurg 92: 766-770, 2000

12) Lee KL, Terris MK: Luteinizing hormone-releasing hormone agonists and meningioma: a treatment dilemma. Urology 62: 351i-351iii, 2003

13) Markwalder TM, Gerber HA, Waelti E, Schaffner T, Markwalder RV: Hormonotherapy of meningiomas with medroxyprogesterone acetate. Immunohistochemical demonstration of the effect of medroxyprogesterone acetate on growth fractions of menin- gioma cells using the monoclonal antibody Ki-67. Surg Neurol 30: 97-101, 1988

14) Markwalder TM, Seiler RW, Zava DT: Antiestrogenic therapy of meningiomas - a pilot study. Surg Neurol 24: 245-249, 1985

15) Markwalder TM, Waelti E, Konig MP: Endocrine manipulation of meningiomas with medroxyprogesterone acetate. Effect of MPA on receptor status of meningioma cytosols. Surg Neurol 28: 3-9, 1987

16) Matsuda Y, Kawamoto K, Kiya K, Kurisu K, Sugiyama K, Uozumi T: Antitumor effects of antiprogesterones on human meningioma cells in vitro and in vivo. J Neurosurg 80: 527-534, 1994

17) Matsumoto M, Sanpei K, Ohishi H, Seiki Y, Terao H, Kudo M: [Spontaneous regression of a meningioma in Meckel's cave. Case report]. Neurol Med Chir (Tokyo) 28: 925-929, 1988 (Jpn, with Eng abstract)

18) Nakamura M, Roser F, Michel J, Jacobs C, Samii M: The natural history of incidental meningiomas. Neurosurgery 53: 62-70, 2003

19) Olson JJ, Beck DW, Schlechite J, Loh PM: Hormonal manipulation of meningioma in vitro. J Neurosurg 65: 99-107, 1986

20) Schrell UM, Adams EF, Fahlbusch R, Greb R, Jirikowski G, Prior R, Ramalho-Ortigao FJ: Hormonal dependency of cerebral meningiomas. Part 1: Female sex steroid receptors and their significance as specific markers for adjuvant medical therapy. J Neurosurg 73: 743-749, 1990

21) Smith JS, Hinojosa AQ, Smith MH, Bollen AW, McDermott MW: Sex steroid and growth factor profile of a meningioma associated with pregnancy. Can J Neurol Sci 32: 122-127, 2005

22) Waelti ER, Markwalder TM: Endocrine manipulation of meningiomas with medroxyprogesterone acetate. Effect of MPA on growth of primary meningioma cells in monolayer tissue culture. Surg Neurol 31: 96-100, 1989

23) Yano S, Kuratsu J; Kumamoto Brain Tumor Research Group: Indications for surgery in patients with asymptomatic meningiomas based on an extensive experience. J Neurosurg 105: 538-543, 2006

Address reprint requests to: Jun Shimizu, M.D., Medical Engineering Laboratory, Research Center for Medical Science, The Jikei University School of Medicine, 3-25-8 Nishi-shinbashi, Minato-ku, Tokyo 105-8461, Japan. 